\title{
ARTITRS
}

Universidade Estadual de Campinas, Campinas, Brasil.

MARCELA VASCO

\section{A REPRESENTAÇÃO DA TRAGÉDIA DE MARIANA: FOTOGRAFIAS ENTERRADAS E IMAGENS SOBREVIVENTES}

\section{RESUMO}

Este texto ensaístico apresenta um processo de investigação a partir das imagens produzidas sobre a tragédia do rompimento da barragem de rejeitos de Fundão, no complexo da Alegria, da mineradora Samarco (controlada pelas empresas Vale e BHP Billiton), em Bento Rodrigues, distrito da cidade de Mariana, Minas Gerais. Através das fotografias jornalísticas e artísticas que procuraram revelar o ocorrido, busco analisar a noção de desastre e a representação acionadas para classificar e retratar essa tragédia e, com base nos questionamentos extraídos desta breve aná-

palavras-chave Mariana; desastre; fotografia; imagem; montagem. lise, proponho um trabalho de deformação, montagem e restituição das imagens como forma de jogar com metáforas a partir dos restos que sobraram. 


\section{INTRODUÇãO}

Ao cursar duas disciplinas de antropologia visual no segundo semestre de 2016' cujas propostas eram incentivar os alunos a trabalharem com imagens da própria pesquisa, pensei que o fato de não ter iniciado o trabalho de campo e não dispor de imagens produzidas por mim não fosse culminar em um problema. De certa forma, eu estava enganada - e este texto é justamente sobre os desafios inesperados que encontrei nesse processo e como tentei, de forma prática, solucioná-los através de um trabalho de deformação, montagem e restituição de imagens.

Minha pesquisa de doutorado investiga fotografias desaparecidas na tragédia do rompimento da barragem da mineradora Samarco (controlada pela Vale e pela BHP Billiton) em Bento Rodrigues, distrito da cidade de Mariana (MG). Mesmo tratando do desaparecimento da imagem e do invisível, como inúmeras imagens haviam sido produzidas sobre o desastre, resolvi recorrer a algumas delas nas aulas para exercitar os trabalhos de montagem propostos pelas docentes. Entretanto, procurando por essas imagens me dei conta de que nenhuma delas cumpria a proposta do trabalho e uma questão fundamental surgiu desse descontentamento: como representar a tragédia?

As fotografias produzidas por jornalistas ou fotojornalistas sobre a tragédia do rompimento da barragem de Fundão eram, em grande parte, fotografias belíssimas, mas que pouco ou nada diziam sobre tragédia. Essa questão tem raízes profundas. Eliane Brum (2015), em matéria para o El País, questiona: "Que Guernica poderá ser pintada diante da obra da Samarco, a mineradora que pertence à Vale (antes chamada "do Rio Doce") e à anglo-australiana BHP Billiton?” Guernica, sabemos bem, é o painel pintado por Pablo Picasso em 1937 para representar o bombardeio da cidade de Guernica, na Espanha, por aviões alemães, em apoio ao general Franco. Picasso recorreu ao cubismo para pintá-lo e costumava se referir a ele como uma obra que não havia sido feita para decorar apartamentos. Ao recorrer à Guernica, Eliane Brum está questionando justamente a representação da tragédia: "Talvez fosse necessário mais um movimento de vanguarda na arte, que desse conta do excesso de real da realidade" (Ibid., 2015).

1 As disciplinas citadas são "Tópicos avançados em modos de conhecimento e suas expressões: experiências e trajetórias I - antropologia e imagem II", ministrada pela Prof. ${ }^{a}$ Dr. ${ }^{a}$ Fabiana Bruno e oferecida pelo Programa de Pós-Graduação em Ciências Sociais da Universidade Estadual de Campinas; e "Antropologia visual", ministrada pela Prof. ${ }^{\text {a }}$ Dr. ${ }^{\text {a }}$ Andrea Barbosa e oferecida pelo Programa de Pós-Graduação em Ciências Sociais da Universidade Federal de São Paulo. Agradeço a Fabiana e Andrea bem como aos colegas das duas turmas pelos debates mobilizados em sala e pelas sugestões dirigidas ao meu trabalho - muitas presentes neste texto. 
Entretanto, não se trata de assumir a posição de Claude Lanzmann, por exemplo, para quem a Shoah é irrepresentável. Encontramos um debate interessante sobre a representação da tragédia no livro Imagens apesar de tudo, de Georges Didi-Huberman (2012). Nele, Didi-Huberman escreve sobre "as quatro imagens arrancadas ao inferno de Auschwitz", que são quatro fotografias tiradas às pressas a partir do crematório $\mathrm{V}$ por um membro do Sonderkommando e enviadas para fora de Auschwitz dentro de um tubo de creme dental. As fotos, protagonistas da exposição Memoire des camps: photographies des camps de concentration et d'extermination nazis 1933-1999², realizada em Paris no ano de 2001, são, para Didi-Huberman (Ibid., 19), os testemunhos dos que sucumbiram e conseguem tornar o inferno que foi Auschwitz ao menos imaginável. Lanzmann, porém, irá criticá-lo por esse texto ao argumentar que Didi-Huberman faz dessas fotografias a imagem toda da Shoah, o que acaba por destruir todas as outras imagens. Para ele, essas quatro fotografias são imagens fetiche e nada se ganha ao mostrá-las. Sua posição é dogmática: a Shoah é irrepresentável e inimaginável.

Ainda que o tema possa ser aprofundado para além desse debate, para a proposição a ser desenvolvida neste trabalho interessa o ponto em que Didi-Huberman rebate às críticas de Lanzmann defendendo que "a imagem toda da Shoah não existe: não porque a Shoah seja inimaginável por direito, mas porque a imagem se caracteriza, de facto, por não ser um todo" (Ibid., 110). Esse ponto se interliga ao desenvolvimento deste trabalho porque, ao recorrer às imagens da tragédia de Mariana, minha intenção era semelhante. Ainda que inconscientemente, buscava por imagens que compreendessem toda a tragédia de Fundão.

No entanto, nesse mesmo livro, Didi-Huberman (Ibid., 52-55) afirma ainda que a dificuldade com as imagens existe porque ora pedimos muito a elas, quando são inadequadas e até mesmo inexatas, ora pedimos muito pouco, relegando-as à esfera de documentos, ilustrações de testemunhos, como se elas mesmas não fossem capazes de testemunhar por si sós. Essas duas formas de dar atenção às imagens, hipertrofiá-las ("querer ver tudo nelas", "transformá-las em ícones") ou insensibilizá-las ("não ver nelas mais do que um documento"), são, segundo o autor, incapazes de nos ajudar.

Dessa forma, se as imagens não conseguiam oferecer toda dimensão da tragédia - e é claro que elas não conseguiriam - não era porque fossem deficientes, mas porque eu exigia tudo delas, não sabia ainda olhá-las, tampouco aceitar aquilo que me ofereciam. Passei a questionar, então: o que aquelas imagens mudas e problemáticas diziam? Como era possível pensar a tragédia com aquelas imagens? E, claro, como eu poderia,

2 Curadoria de Pierre Bonhomme e Clément Chéroux. 
através desse dizer mudo das imagens, encontrar a representação da tragédia à qual a pesquisa se propunha?

\section{O DESASTRE SOB UMA PERSPECTIVA ANTROPOLÓGICA}

Em 5 de novembro de 2015, a barragem de Fundão no complexo da Alegria da mineradora Samarco se rompeu e despejou mais de 60 milhões de metros cúbicos de rejeitos da mineração de ferro sobre Bento Rodrigues, distrito da cidade de Mariana (MG), seguindo pelo rio Gualaxo do Norte e pelo rio do Carmo até atingir o Rio Doce, por onde cortaria os estados de Minas Gerais e Espírito Santo até desaguar no oceano, na praia de Regência (ES).

Com o sedimento, metais pesados foram misturados às águas dos rios, causando a morte de peixes, aves e, em diversos pontos, do próprio Rio Doce e alguns de seus afluentes. Pescadores, ribeirinhos, agricultores, assentados da reforma agrária e o povo indígena Krenak bem como os moradores das cidades localizadas ao longo dos rios atingidos foram afetados pelo desastre. Embora tenha gerado polêmica a posição do governo federal ao classificar o desastre como "natural", tendo posteriormente afirmado se tratar de um desastre "tecnológico", e apesar de grande parte da mídia o ter caracterizado como "ambiental", o rompimento da barragem de Fundão tem proporções ainda mais complexas.

Conforme alerta Norma Valencio,

o uso do qualificativo "natural" a desastres catastróficos, como o relacionado ao rompimento de barragem da Samarco, se torna uma agressão simbólica àqueles severamente prejudicados nessas situações, porque o fator causador não teria personalidade jurídica a responder em tribunais. É de notar que a sua eventual substituição pelo qualificativo "tecnológico" também poderia ser limitante, pois seu uso dominante não o associa às relações sociais, limitando-se puramente a coisas - aos diques de contenção, às substâncias químicas dos rejeitos e afins - como se nelas estivesse contido o mal deflagrado e a adoção de novas tecnicalidades resolvesse o problema. [...] o mesmo se poderia dizer em relação ao qualificativo "ambiental" que, em termos práticos, salienta apenas questões ecológicas passíveis de

3 Ver "Procuradora critica decreto de Dilma que classifica desastre como 'natural", do jornal 0 Globo, disponível em: <https://goo.gl/ag9ctn>. Acesso em: 6 dez. 2017. Ver ainda "Documento mostra que, para governo, tragédia em Mariana não foi causada pela natureza", do Diário Oficial da União, disponível em: <https://goo.gl/T3hxmf>. Acesso em: 6 dez. 2017. 
manejo técnico deixando a reboque, num jogo de esconde, os sujeitos sociais e as lógicas operativas que forjam e recrudescem tais tragédias (Valencio 2016, 42).

Nesse sentido, o conceito de desastre mobilizado neste trabalho visa abordar o impacto social nos modos de vida dos atingidos.

Renzo Taddei (2016), ao defender a abordagem do desastre sob uma perspectiva antropológica, afirma que o "desastre jamais está 'na' natureza, e sim na relação que se tem com ela" (Taddei 2016 apud Oliver-Smith 1999). Para isso, o autor nos oferece o exemplo de sua pesquisa realizada no sertão nordestino. Taddei se volta primeiro para a caatinga, um ecossistema formado sobretudo por vegetação xerófita, capaz de sobreviver a situações de extrema seca. Estando a caatinga há provavelmente milhares de anos presente no chamado "polígono das secas", é evidente que aquela região enfrenta a escassez de água já há muito tempo. Durante grande parte desse período, animais e populações nativas enfrentaram o problema migrando pelo território à procura de água. o povoamento em núcleos permanentes teria sido, segundo o antropólogo, o responsável por expor a população a uma "rigidez espacial inconciliável com os fluxos e variações climáticas da região" (Taddei 2016, 2). Nesse sentido, o "elemento desastroso" no caso da seca nordestina não é exatamente a escassez de água, mas sim a forma de domínio e uso da terra implantados pelos europeus no país. Dessa forma, Taddei defende que o "desastre está praticamente embutido nas formas de organização econômica e política brasileiras" (Taddei 2016 apud Taddei and Gamboggi 2010).

No caso das barragens, de acordo com o Departamento Nacional de Produção Mineral (Freitas, Silva e Menezes 2016, 26), o Brasil possui 662 barragens e cavas exauridas com barramento distribuídas em 164 municípios pelo país. Oitenta por cento delas são classificadas, pela categoria de risco, com baixo risco de desastres - classificação dada à barragem de Fundão. Outras 5\% são consideradas de alto risco. Assim, "podemos considerar que temos um grande conjunto de sérias ameaças e riscos de desastres em barragens de mineração espalhado pelo país".

Sobre o aspecto econômico, segundo dados disponibilizados pelo grupo de pesquisa Política, Economia, Mineração, Ambiente e Sociedade (Milanez et al. 2015), o Brasil foi um dos cinco países responsáveis por dois terços das exportações globais de minérios, o que aprofundou a dependência econômica do país com relação ao setor minero-exportador. "A participação dos minérios na exportação do país passou de 5\% para 14,5\%, tendo o minério de ferro correspondido a 92,6\% desse total" (Wanderley et al. 2016, 30). Trata-se de um modelo de desenvolvimento estimulado pelo governo federal que é altamente predatório e trata a natureza como 
fonte de exploração. Nesse contexto, a barragem de Fundão, que entrou em operação em 2008 (quando o preço do minério atingia o ápice), teve seu licenciamento ambiental "realizado por instituições que passam por intenso processo de precarização e interferência política, sendo, mesmo assim, sua aprovação vinculada a uma série de condicionantes, nem sempre cumpridas de forma efetiva" (Ibid., 34).

Na região atingida nas cercanias de Mariana, estima-se que em muitas localidades até 95\% da atividade econômica seja baseada na extração do minério de ferro, de modo que a interrupção das atividades da Samarco ocasionou um colapso da economia regional. Essa questão expõe claramente a dependência econômica com relação à extração de minérios e o paradoxo dos malefícios dessa dependência. A esse respeito Valencio (2016) alerta que, embora inicialmente o altruísmo seja o comportamento social preponderante, após um breve período observa-se a prática da chamada slow violence contra os atingidos em contexto de desastre. Em Mariana, podemos observar várias práticas de culpabilização das vítimas por parte dos moradores, muitos trabalhadores direta ou indiretamente ligados à Samarco, que acusam os atingidos de serem responsáveis pelo alto índice de desemprego na região4.

Nesse sentido, as dimensões da tragédia são muito mais complexas do que as vagas definições do desastre apontam. Retomar o desastre sob uma perspectiva antropológica torna-se, portanto, uma maneira de aprofundar a análise:

No contexto mineiro, cientistas sociais apontaram que a comunidade de Bento Rodrigues tinha receio de rompimento de barragem há anos e, após a concretização do desastre, o assédio da empresa teria se tornado constante, constrangendo as condições reivindicativas comunitárias. Já no contexto capixaba, um estudo similar apontou a junção de aspectos concretos e simbólicos; graves problemas no abastecimento hídrico, na irrigação de lavouras, na pesca e no turismo e lazer, além dos danos ecológicos, associaram-se à violência policial contra manifestantes e à dor comunitária de presenciar o rio Doce em agonia, contrapondo-se a sua memória afetiva do lugar. Tais esgarçamentos e descontinuidades na vida social não ocorreram somente nesse desastre, mas em inumeráveis outros, nos quais cientistas sociais precisariam ser apoiados para se debruçar com densidade de análise (Valencio 2016, 43-44).

4 Estima-se cerca de 13 mil desempregados após a interrupção das atividades da Samarco. Ver "Moradores de Mariana culpam vítimas do desastre por aumento no desemprego", da Vice (2016), disponível em: <https://goo.gl/qA5Bbw>. Acesso em: 6 dez. 2017. 


\section{IMAGENS DA LAMA}

A forma como a tragédia de Mariana foi representada, tanto pela imprensa como por grande parte dos fotógrafos a se aventurar pela lama, necessita de análise. No caso das fotografias feitas em Bento Rodrigues, é sintomática a ausência dos atingidos nas imagens. Sua presença é marcada somente pelo rastro dessa ausência: um boné abandonado sobre a lama, um garfo, um livro, um sofá.

As imagens jornalísticas almejam o impacto imediato. A mais difundida pelos meios de comunicação exibe um carro sobre o muro de uma casa cujo telhado foi varrido pela lama. Essa imagem recoloca o debate da dimensão da tragédia. Cerca de 60 milhões de metros cúbicos de lama arrastando muros, telhados e móveis por onde passava. Lama capaz de lançar um carro sobre o muro de uma casa, tamanha força. Essas imagens dramáticas e apelativas preencheram exaustivamente os telejornais até ficarem saturadas e serem substituídas na semana seguinte, quando ocorreram atentados terroristas em Paris, fazendo o desastre da barragem de Fundão aos poucos passar a ser notícia velha.

No entanto, a imagem do carro sobre o muro, além da exaustão, sempre despertou a minha atenção por outro fator. 0 ângulo dessa imagem, tirada de um helicóptero, seria um dos mais usados para falar da tragédia. Nas fotografias feitas por Pedro Mascaro com seu pai, Cristiano Mascaro, sete meses depois para a revista Piauí (Mascaro and Mascaro 2016), esse também foi o ponto de vista escolhido para falar da tragédia: fotografias do alto do epicentro do desastre, tiradas com auxílio de um drone.

Em casos como esse, cujas dimensões atingem uma larga extensão geográfica, as imagens de satélite são recorrentes para abarcar as proporções do desastre. No entanto, qual sua efetividade para mostrar a dimensão de um desastre? Aqui entramos em um problema de posicionamento - não só do olhar, mas do campo teórico acionado para definir o conceito de desastre. 0 rompimento da barragem de Fundão é ainda hoje, por grande parte da imprensa nacional e internacional, descrito como o maior desastre ambiental da história do Brasil. Como vimos anteriormente, porém, suas raízes são político-econômico-sociais. Nesse aspecto, o pecado das imagens de satélite é que quanto a isso elas se calam.

Eduardo Sterzi (2016) para a revista Zum escreve que

Somente imagens de satélite conseguiram abarcar por completo a catástrofe - no entanto, se ganhamos, assim, em visão do todo, perdemos em contato com o real. A fotografia 
se torna mapa, abstração. $O$ todo apreendido e oferecido por uma imagem de satélite é um todo que perdeu concretude, espécie de pura imagem desancorada do mundo. A catástrofe parece exigir um olhar capaz de movimentar-se entre o plano máximo (o território totalmente modificado, as populações afetadas, os rios destruídos, os reflexos no oceano etc.) e o plano mínimo (não só a extinção de algumas espécies, mas cada animal morto; não só as comunidades deslocadas, mas cada objeto deixado para trás...). Por mais que se concentre no plano mínimo - e fotografar é, necessariamente, recortar o real -, o fotógrafo não pode deixar de aludir, através do mínimo, ao máximo.

Bruno Veiga, fotógrafo de quem fala Sterzi nessa matéria, parece resolver o problema com seu ensaio "Deserto vermelho". As fotografias de Veiga, no entanto, vacilam em outro aspecto: são esteticamente impecáveis. De que tragédia é possível falar diante da beleza dessas imagens? Essa é uma questão a assombrar cada fotografia de tragédia. É possível a fotografia de um desastre dessa proporção ser bela?

As quatro fotografias do Sonderkommando analisadas por Didi-Huberman (2012) são impreteríveis. Exatamente por isso, alguns poderiam dizer que são mal enquadradas. No entanto, a técnica peca justamente em favor do ato fotográfico. Sua urgência é parte da história. Nas fotografias do desastre da Samarco, no entanto, muitos fotógrafos estiveram em Bento Rodrigues à procura de uma tragédia agradável aos olhos. Talvez 0 maior exemplo disso seja Christian Cravo, que deu uma declaração a um jornal de Minas (Midlej 2016) dizendo que "O grande desafio que [teve] foi encontrar alguma beleza numa situação obscura como essa. E isso só foi possível depois que [viu] o episódio com certa 'frieza', depois de um tempo do rompimento da barragem".

Ser capaz de ver beleza na tragédia é, sem dúvida, uma questão cultural. Davi Kopenawa e Bruce Albert $(2015,432)$ relatam a ida do xamã yanomami à cidade e, diante do céu avermelhado, Kopenawa não vê beleza nenhuma:

Onde os brancos vivem, o céu é baixo e eles não param de cozer grandes quantidades de minério e de petróleo. Por isso as fumaças de suas fábricas sobem sem trégua para o peito do céu. Isso o torna muito seco, quebradiço e inflamável como gasolina. Ressecado pelo calor, torna-se frágil e se desfaz em pedaços, como uma roupa velha. Tudo isso preocupa muito os xapiri. 
Kopenawa diz ainda que os olhos dos brancos estão estragados pela fumaça do metal e pelo pó de cegueira. Para ele, não conseguimos enxergar direito porque arrancamos os minérios da terra, os trituramos e aquecemos nas fábricas. "Ele então exala uma poeira fina, que se propaga como uma brisa invisível em suas cidades. É uma coisa de feitiçaria perigosa, que entra nos olhos e vai estragando a vista" (Kopenawa e Albert 2015, 362). A fumaça arrancada dos minérios é ao mesmo tempo a que nos cega e colore o céu das cidades. Cegos, contemplamos o céu inflamado.

\title{
FOTOGRAFIAS ENTERRADAS E IMAGENS SOBREVIVENTES
}

Diante das questões anteriormente colocadas, como poderíamos, apesar de tudo, pensar com as imagens produzidas sobre o desastre de Mariana? Se elas não falavam exatamente sobre o que eu gostaria que falassem, tentei, então, manipulá-las e montá-las. Intervir nessas imagens era uma maneira de torná-las minhas e montá-las, de fazê-las falar de tragédia.

De início, reuni todas essas fotos, imagens da imprensa, imagens de satélite, fotografias dos Mascaro, de Veiga e de Cravo, as imprimi e depois as enterrei em meu jardim. Queria que, com isso, elas tivessem ao menos algum contato com a lama. Depois de uma semana, após resistirem a pancadas de chuva e à fome dos insetos, foram desenterradas para, enfim, serem montadas.

A respeito da montagem, Walter Benjamin (Didi-Huberman 2016) defende a necessidade de se escovar a contrapelo, ou seja, tentar sair do fluxo de imagens e escovar no revés do pelo para, assim, descobrir seus intervalos e suas descontinuidades. É montando que as imagens tomam posição e expõem os conflitos e paradoxos da história.

\begin{abstract}
A montagem seria para as formas o que a política é aos atos: é preciso que estejam juntas as duas significações da desmontagem que são o excesso das energias e a estratégia dos lugares, a loucura de transgressão e a sabedoria de posição. Walter Benjamin, me parece, nunca parou de pensar lado a lado esses dois aspectos da montagem como sendo da ação política (Ibid., 2).
\end{abstract}

Nesse sentido, como escovar a contrapelo e montar as imagens do desastre? A noção de imagem acionada para isso aponta que elas não são intrinsecamente "boas" ou "más"; por outro lado, dependem também do que fazemos delas e de como as olhamos. A imagem não contém em si um único significado. Mudas, se reservam à polissemia do não dizer.

Didi-Huberman (2015a), no ensaio "Pensar debruçado", diferencia, de um lado, aqueles que pretendem ver tudo de cima e se libertar do mundo 
sensível e, de outro, os que se debruçam para pensar e apostam na experiência sensível. 0 autor denomina essas duas maneiras de olhar, respectivamente, de vista sobrepujante e vista abrangente. Na primeira, a visão estabelece uma postura de recuo e o objeto olhado lá embaixo está separado do olho que olha, é inatingível. O olhar busca, através dela, um saber puro, imaculado. Na segunda, ao contrário, o objeto sobe em direção ao olho, que vai e vem, tornando-se sensível ao que vê e oferecendo a oportunidade de tocar o objeto do saber e se deixar levar por suas seduções, ilusões e meandros. Seu saber é um não-saber.

Olhar de cima, porém, é sempre correr o risco de cair. Com base nessas definições, será que para melhor saber é necessário obrigatoriamente assumir somente uma das duas posições: afastar-se ou se aproximar-se? Segundo Didi-Huberman, apenas duas maneiras de olhar para as imagens servem aos interesses de quem olha. As fotografias de satélite buscam justamente esse saber puro do olhar apartado. Minha intenção era, diferentemente, debruçar-me sobre as imagens e me deixar ser atingida por aquilo que olhava.

Dessa forma, coloquei todas as fotos desenterradas sobre minha mesa de montagem e me debrucei sobre elas. Porém, ainda faltava alguma coisa. Recorri a outro tipo de imagem, que chamarei aqui de fotografias sobreviventes. Encontrei em uma matéria do Brasil de Fato intitulada "O adeus a Bento Rodrigues” (Freire 2016) as fotografias de Manuel Marcos Muniz, o Marquinhos. São algumas das fotografias que não estavam em Bento Rodrigues quando a lama devastou tudo. Marquinhos é hoje um dos poucos moradores a possuir fotografias de Bento antes da lama. As muitas outras continuam soterradas.

Ainda que eu não soubesse o que fazer com as fotos de Marquinhos, também as coloquei sobre minha mesa. Montá-las com as outras imagens me parecia uma maneira de restituir pessoas e memórias às imagens. A presença ausente do atingido era substituída por sua evidência.

figura 1

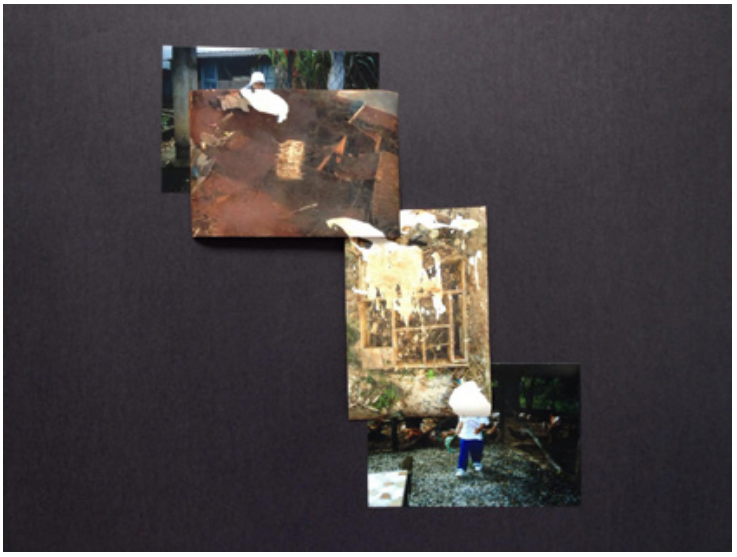


Nessa primeira montagem, os brancos das fotos desenterradas provocados pela raspagem e umidade guiam o aparecimento e desaparecimento na imagem. o branco é, ao mesmo tempo, o que deixou de aparecer pelo rompimento da barragem e a lacuna que tentamos preencher. $\mathrm{O}$ branco tenciona também a memória. Às vezes, quando nos esquecemos de algo dizemos que "deu branco". Destruição está necessariamente ligada ao esquecimento, mas sua relação não é tão direta nem tão simples. Em Bento Rodrigues, o distrito mais destruído pelo rompimento da barragem, várias são as iniciativas dos antigos moradores com a finalidade de recolher lembranças: desenhos de como era o lugar, histórias, memórias... Um esforço para não esquecer, apesar da destruição.

Olhando para essa montagem em outro sentido, vemos que o caminho dos brancos nas imagens escolhidas cria ainda uma espécie de monstro. A cabeça, em uma das pontas, é acompanhada por duas imagens aéreas do distrito destruído e, na outra ponta, o corpo da criança. As duas fotografias da destruição são seu pescoço, o que sustenta a cabeça. A destruição é aqui uma marca corporal dos atingidos, faz parte de quem eles são e foi incorporada.

Por último, as imagens da destruição que se sobrepõem às fotos de como era Bento antes da tragédia, imagens sobreviventes. Como o rompimento da barragem alterou a vida dessa garota?

figura 2

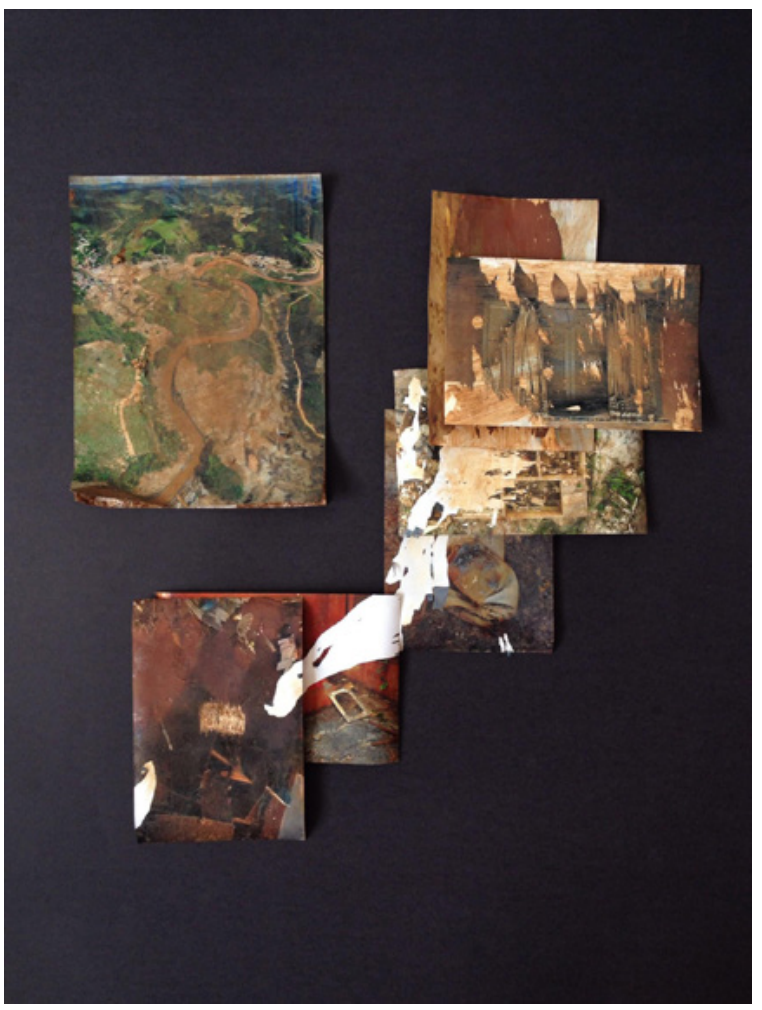


Essa segunda montagem explora de forma diferente os brancos provocados pela raspagem das fotos. Aqui eles se encaixam, desenhando outro percurso para o rio. Um percurso permeado por muitas perdas. As fotografias se sobrepõem, se recortam, se fundem e se montam. Transformam-se assim no próprio rio. Um rio de brancos, perdas e abandonos, correndo para lugar nenhum.

figura 3

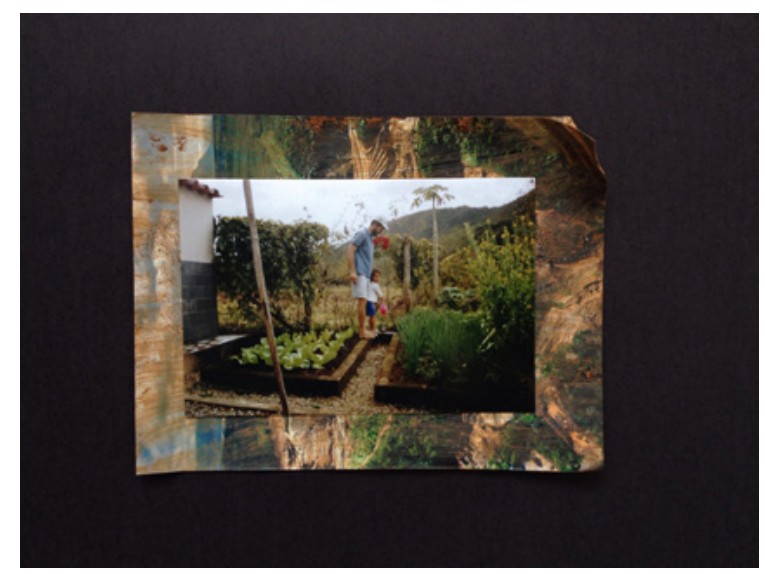

Nessa terceira montagem, vemos apenas uma fotografia sobrevivente colocada sobre uma imagem aérea feita por um drone. Em alguns pontos elas parecem se mesclar. O muro ao lado esquerdo se confunde com o céu, a madeira em primeiro plano termina em uma precipitação. 0 homem e sua filha se equilibram sobre a imagem de baixo. Eles se sustentam apesar de toda a tragédia. Essa montagem é metáfora das fotos que sobreviveram. Imagens sobreviventes tal como aqueles que resistiram a um naufrágio. Aqueles que restaram, que irão nos ajudar a pensar por imagens essa tragédia.

figura 4

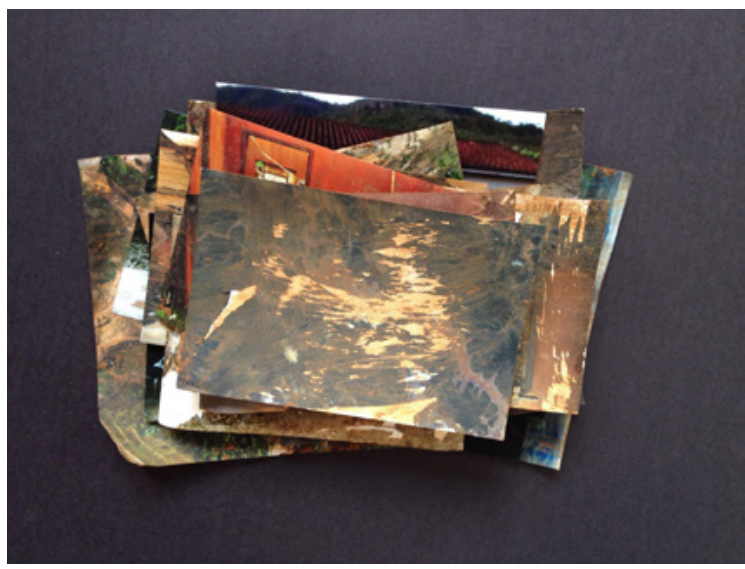


Nessa montagem, temos em primeiro plano uma foto de satélite bastante raspada e, abaixo dela, diversas camadas de outras imagens - inclusive fotografias sobreviventes. Vemos, por exemplo, o telhado da casa de Marquinhos. Para dar conta de cada uma dessas imagens, seria preciso mergulhar na montagem. O movimento aqui é vertical. São camadas de diferentes significados. Para vê-las é preciso escavar, como fazem os arqueólogos em Mariana à procura do que restou. Sozinha, a imagem de satélite não nos oferece nada disso. É preciso se debruçar para ver.

figura 5

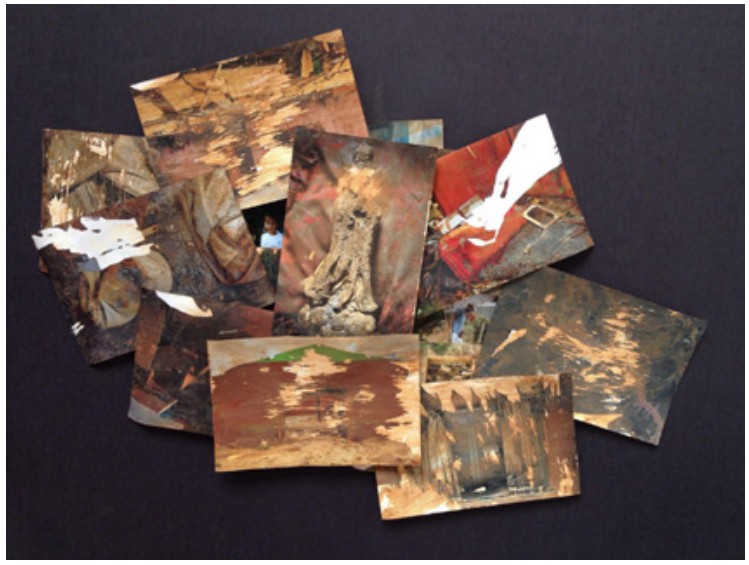

Por fim, na última montagem, temos várias fotos espalhadas sobre o fundo preto. Ao centro, a santa com o rosto raspado. Olhando com mais cuidado, percebemos a garota ao lado esquerdo e, mais à direita, ela com o pai. Esses retratos de família, no entanto, são sufocados pelas imagens da destruição. Suas vidas passam a ser enquadradas pela tragédia.

\section{APONTAMENTOS FINAIS}

Procurei neste processo de trabalho, com a deformação e montagem das imagens da tragédia do rompimento da barragem de Fundão, propor uma nova forma de olhar para as imagens produzidas. Enterrar e deformar as fotografias foi uma maneira de tirar a evidência do reconhecível na imagem e conseguir jogar com metáforas a partir de seus restos. Quando se deixa de ver o reconhecível na imagem, só se vê a deformação.

Didi-Huberman (2015b), quando trata de restituições, afirma que só é possível falar de restos usando os próprios restos. Fala-se em "tirar uma foto", mas o autor questiona: não seria preciso em algum momento devolvê-la? A restituição é, assim, para o autor, resultado de uma reflexão política e de um posicionamento do conhecimento. Restituir "diz ao mesmo tempo da transformação de um objeto e de sua substituição por um outro" (Ibid., 208). 
Nesse sentido, a partir dos restos, procurei complexificar a noção de desastre acionada por jornalistas e fotógrafos e restituir as imagens da tragédia aos atingidos, mobilizando uma perspectiva que abarcasse o âmbito social desse desastre. Ao borrar as dimensões do desastre pretendidas pelas fotografias jornalísticas e dos Mascaro, ao deformar a beleza das fotografias de Veiga e Cravo e ao somar a elas as fotografias sobreviventes de Marquinhos, busquei refletir sobre a representação da tragédia do rompimento da barragem de Fundão e propor um novo modo de olhar cujo intuito foi abranger o intangível de um desastre que devastou vidas, memórias, residências, projetos, modos de vida e muito mais.

\section{REFERÊNCIAS BIBLIOGRÁFICAS}

Brum, Eliane. 2015. A lama. El País, 30 nov. 2015. Disponível em: <https://goo.gl/T9xNHf>. Acesso em: 6 dez. 2017.

Didi-Huberman, Georges. 2012. Imagens apesar de tudo. Lisboa: KKYM.

Didi-Huberman, Georges. 2015a. Pensar debruçado. Lisboa: KKYM.

Didi-Huberman, Georges. 2015b. Devolver uma imagem. In Pensar a imagem, org. Emmanuel Alloa, 7-19. Belo Horizonte: Autêntica.

Didi-Huberman, Georges. 2016. Remontar, remontagem (do tempo). Caderno de Leituras, no. 47: [1-7].

Freire, Simone. 2016. 0 adeus a Bento Rodrigues. Brasil de Fato, 28 out. 2016. Disponível em: <https://goo.gl/ikTeiA>. Acesso em: 6 dez. 2017.

Freitas, Carlos Machado, Mariano Andrade da Silva e Fernanda Carvalho de Menezes. 2016. 0 desastre na barragem de mineração da Samarco: fratura exposta dos limites do Brasil na redução de risco de desastres. Ciência e Cultura, vol. 68, no. 3: 25-30.

Kopenawa, Davi e Bruce Albert. 2015. A queda do céu: palavras de um xamã yanomami. São Paulo: Companhia das Letras.

Mascaro, Cristiano e Pedro Mascaro. 2016. A terra devastada: as marcas da tragédia sete meses depois. Revista Piauí, $1^{\circ}$ ago. 2016. Disponível em: <https://goo.gl/ hJKrmv>. Acesso em: 6 dez. 2017.

Midlej, Roberto. 2016. Livro de fotografias de Christian Cravo revela marcas da tragédia de Mariana, em Minas. Correio: o que a Bahia quer saber, 20 jul. 2016. Disponível em: <https://goo.gl/Bm7vcf>. Acesso em: 6 dez. 2017. 
Milanez, Bruno, Luiz Wanderley, Maíra Mansur, Raquel Pinto, Ricardo Gonçalves, Rodrigo Santos e Tádzio Coelho. 2016. Antes fosse mais leve a carga: avaliação dos aspectos econômicos, políticos e sociais do desastre da Samarco/Vale/BHP Billiton. Marabá: Iguana.

Oliver-Smith, Anthony. 1999. "What is a disaster? Anthropological perspectives on a persistent question". In: Oliver-Smith, A; Hoffman, S. (orgs.), The angry Earth: disaster in anthropological perspective. New York: Routledge.

Sterzi, Eduardo e Bruno Veiga. 2016. Fotografia e catástrofe: Mariana (MG). Revista Zum, 3 jun. 2016. Disponivel em: <https://goo.gl/1jynF8>. Acesso em: 6 dez. 2017.

Taddei, Renzo. 2016. Os desastres em uma perspectiva antropológica. ComCiência: revista eletrônica de jornalismo científico, no. 176.

Taddei, Renzo e Ana Laura Gamboggi (orgs). 2010. Depois que a chuva não veio - respostas sociais às secas na Amazônia, no Nordeste e no Sul do Brasil. Fortaleza: Fundação Cearense de Meteorologia e Recursos Hídricos/Instituto Comitas para Estudos Antropológicos.

Valencio, Norma. 2016. Elementos constitutivos de um desastre catastrófico: os problemas científicos por detrás dos contextos críticos. Ciência e Cultura, vol. 68, no. 3: 41-45.

Wanderley, Luiz Jardim, Maíra Sertã Mansur, Bruno Milanez e Raquel Giffoni Pinto. 2016. Desastre da Samarco/Vale/BHP no Vale do Rio Doce: aspectos econômicos, políticos e socio ambientais. Ciência e Cultura, vol. 68, no. 3: 30-35.

\section{MARCELA VASCO}

Doutoranda no Programa de Pós Graduação em Ciências Sociais da Universidade Estadual de Campinas (UNICAMP). Possui mestrado pela

recebido

28.04.2017

aprovado

25.09.2017 Universidade Federal de São Paulo (UNIFESP) e bacharelado pela Universidade Estadual Paulista (UNESP). É integrante do Laboratório Antropológico de Grafia e Imagem (LA'GRIMA) e do Grupo de Pesquisas Visuais e Urbanas da Unifesp (VISURB). 